\title{
KINERJA JACKKNIFE RIDGE REGRESSION DALAM MENGATASI MULTIKOLINEARITAS
}

\author{
Hany Devita ${ }^{\S 1}$, I Komang Gde Sukarsa² ${ }^{2}$ I Putu Eka N. Kencana ${ }^{3}$ \\ ${ }^{1}$ Jurusan Matematika, Fakultas MIPA - Universitas Udayana [Email: hanydevita92@gmail.com] \\ ${ }^{2}$ Jurusan Matematika, Fakultas MIPA - Universitas Udayana [Email: sukarsakomang@yahoo.com] \\ ${ }^{3}$ Jurusan Matematika, Fakultas MIPA - Universitas Udayana [Email: i.putu.enk@ gmail.com] \\ ${ }^{\S}$ Corresponding Author
}

\begin{abstract}
Ordinary least square is a parameter estimations for minimizing residual sum of squares. If the multicollinearity was found in the data, unbias estimator with minimum variance could not be reached. Multicollinearity is a linear correlation between independent variabels in model. Jackknife Ridge Regression(JRR) as an extension of Generalized Ridge Regression (GRR) for solving multicollinearity. Generalized Ridge Regression is used to overcome the bias of estimators caused of presents multicollinearity by adding different bias parameter for each independent variabel in least square equation after transforming the data into an orthoghonal form. Beside that, JRR can reduce the bias of the ridge estimator. The result showed that JRR model out performs GRR model.
\end{abstract}

Keywords: ordinary least square, multicollinearity, Generalized Ridge Regression, Jackknife Ridge Regression

\section{PENDAHULUAN}

Analisis regresi merupakan salah satu alat statistika yang digunakan untuk menggambarkan hubungan antara satu peubah tak bebas dengan satu atau lebih peubah bebas (Bowerman \& O'Connel [1]). Dalam pembentukan model regresi dilakukan pendugaan terhadap parameter regresi dalam model untuk menghasilkan penduga terbaik dengan menggunakan metode kuadrat terkecil. Metode kuadrat terkecil adalah metode untuk menduga parameter dalam model regresi dengan meminimumkan jumlah kuadratnya. Jika penduga tak bias dan ragam minimum tidak dapat dihasilkan maka mengindikasikan adanya multikolinearitas pada model.

Multikolinearitas merupakan suatu keadaan terjadinya hubungan linear antara peubah-peubah bebas dalam model yang menyebabkan model menjadi bias sehingga nilai penduga parameternya menjadi tidak stabil. Untuk mengetahui ada tidaknya masalah multikolinearitas dapat menggunakan nilai Variance Inflation Factory (VIF). Jika nilai VIF > 5 maka peubah bebas dalam model mengalami multikolinearitas (Neter, et al. [5]). Ada berbagai metode yang digunakan dalam mengatasi multikolinearitas yaitu metode regresi stepwise, analisis komponen utama, ridge regression dan generalized ridge regression. Pada setiap metode memiliki kekurangan dan kelebihan namun setiap metode dapat digunakan dalam mengatasi masalah multikolinearitas.

Pada penelitian ini, penulis menggunakan metode Jackknife Ridge Regression yaitu pengembangan dari metode generalized ridge regression dengan lebih menekankan pengurangan bias pada penduga ridge (Ozkale [6]). Tujuan dari penelitian ini adalah untuk mengetahui kinerja Jackknife Ridge Regression dalam mengatasi masalah multikolinearitas dan untuk mengetahui 
kelayakan model yang dihasilkan Jackknife Ridge Regression dengan melihat nilai MSE dan $\mathrm{R}^{2}$ yang dihasilkan pada model.

\section{TINJAUAN PUSTAKA}

\subsection{Analisis Regresi Berganda}

Analisis regresi linear berganda adalah analisis regresi yang menghubungkan antara satu peubah tak bebas $Y$ dengan banyak peubah bebas $X$. Persamaan regresi linear berganda dapat dijabarkan menjadi notasi matriks, sebagai bentuk perluasan dari model regresi linear secara umum yang bertujuan dapat mengindikasikan langkah-langkah penting dalam menemukan solusi. Notasi matriks yang terbentuk dari persamaan regresi linear berganda sebagai berikut:

$$
Y_{n \times 1}=X_{n \times p} \beta_{p \times 1}+\varepsilon_{n \times 1}
$$

dengan;

$n=$ jumlah pengamatan

$p=$ banyaknya parameter

$Y=$ vektor peubah tak bebas

$\beta=$ vektor parameter regresi

$X=$ matriks peubah bebas

$\varepsilon=$ vektor peubah acak (sisaan) normal bebas dengan nilai harapan $E(\varepsilon)=0$ dan matriks ragam-peragam $\sigma^{2}(\varepsilon)=\sigma^{2} I$.

\subsubsection{Pengujian Hipotesis pada Regresi Linear Berganda}

Pengujian hipotesis bertujuan untuk menguji kecocokan model. Terdapat dua pengujian yaitu:

1. Uji $F$ ( Uji Signifikansi Model)

Uji $F$ digunakan untuk menggambarkan ada atau tidak hubungan linear antara peubah tak bebas $\mathrm{Y}$ dengan semua peubah bebas secara simultan yang ada dalam model.

Hipotesis yang diuji:

$$
\begin{aligned}
& H_{0}: \beta_{1}=\beta_{2}=\cdots=\beta_{p-1}=0 \\
& H_{1}: \beta_{k} \neq 0 \text { minimal untuk satu } \\
& \text { nilai } k, k=1,2, \ldots, p-1
\end{aligned}
$$

Statistik ujinya (Neter, et al. [5]) adalah:

$$
F^{*}=\frac{J K R\left(X_{1}, \ldots, X_{p-1}\right)}{p-1} \times \frac{n-p}{J K G\left(X_{1}, \ldots, X_{p-1}\right)}
$$

$$
=\frac{K T R}{K T G}
$$

Kaidah keputusan:

Jika $F^{*} \leq F_{(\alpha, p, n-p-1)}$ maka $H_{0}$ diterima Jika $F^{*}>F_{(\alpha, p, n-p-1)}$ maka $H_{0}$ ditolak

\section{Uji $t$ (Uji Parsial Model)}

Uji $t$ digunakan jika pada uji signifikansi (uji $F$ ) menghasilkan kesimpulan $H_{0}$ ditolak yang berarti minimal ada satu variabel yang berpengaruh siginifikan terhadap model. Tujuan uji $t$ untuk mengetahui ada atau tidak hubungan linear antara peubah tak bebas $Y$ dengan masing-masing peubah bebas yang ada dalam model.

Hipotesis yang diuji:

$$
\begin{aligned}
& H_{0}: \beta_{k}=0 \\
& H_{1}: \beta_{k} \neq 0
\end{aligned}
$$

Statistik ujinya (Neter, et al. [5]) adalah:

$$
t^{*}=\frac{\hat{\beta}_{k}}{\operatorname{Se}\left(\hat{\beta}_{k}\right)}
$$

Keterangan; $\operatorname{Se}\left(\hat{\beta}_{k}\right)=$ standard error penduga koefisien regresi

Kaidah Keputusan:

Jika $\left|t^{*}\right| \leq t_{\frac{\alpha}{2}, n-k-1}$ maka $H_{0}$ diterima

Jika $\left|t^{*}\right|>t_{\frac{\alpha}{2}, n-k-1}$ maka $H_{0}$ ditolak

\subsection{Metode Kuadrat Terkecil}

Metode kuadrat terkecil adalah metode untuk menduga parameter dalam model regresi dengan cara meminimumkan jumlah kuadrat galatnya (Neter, et al. [5]). Vektor koefisien regresi dugaan $\beta_{0}, \beta_{1}, \ldots, \beta_{p-1}$ dituliskan sebagai berikut:

$$
b_{p \times 1}=\left[\begin{array}{c}
\beta_{1} \\
\beta_{2} \\
\vdots \\
\beta_{p-1}
\end{array}\right]
$$

Persamaan normal kuadrat terkecil bagi model linear umum adala

$$
X^{\prime} X b=X^{\prime} Y
$$

Dengan penduga kuadrat terkecilnya adalah:

$$
b_{p \times 1}=\left(X^{\prime} X\right)_{p \times p}^{-1} X^{\prime} Y_{p \times 1}
$$

Untuk model regresi, penduga-penduga kuadrat terkecil ini juga merupakan penduga 
kemungkinan maksimum dan memenuhi asumsi-asumsi yang harus dipenuhi yaitu galat menyebar normal dengan nilai tengah 0 dan ragam konstan $\sigma^{2}$,tidak terdapat korelasi antar galat, dan tidak terdapat pola hubungan yang terbentuk antar peubah-peubah bebas.

\subsection{Generalized Ridge Regression}

Dalam metode Generalized Ridge Regression (GRR) dilakukan transformasi terhadap data sehingga peubah bebas menjadi peubah bebas yang orthogonal[4] terhadap peubah tak bebas. Pertama-tama diasumsikan bahwa $\Lambda$ merupakan matriks $p \times p$ dengan anggota dari diagonal utamanya merupakan nilai eigen $\left(\lambda_{1}, \lambda_{2}, \ldots, \lambda_{p}\right)$ dari matriks $X^{\prime} X$ dan jika $T_{p \times p}$ merupakan matriks orthogonal dari vektor eigen yang bersesuaian dengan $\lambda$, maka $T^{\prime} X^{\prime} X T=\Lambda$. Misalkan $Z=X T$ dan $\alpha=T^{\prime} \beta$. Model linear persamaan regresi yang dihasilkan menjadi $Z \alpha+\varepsilon$. Penduga yang diperoleh dari metode kuadrat terkecil menjadi $\hat{\alpha}=\Lambda^{-1} Z^{\prime} y$. Vektor penduga parameter awal dapat dihitung menjadi $\hat{\beta}=T \hat{\alpha}$. Penduga GRR merupakan solusi dari $(\Lambda+\mathrm{K}) \hat{\alpha}_{G R}=$ $Z^{\prime} y$, dengan $K$ merupakan matriks diagonal dengan anggota $\left(k_{1}, k_{2}, \ldots, k_{p}\right)$. Koefisien generalized ridge pada model awal yaitu

$$
\begin{gathered}
\hat{\beta}_{G R}=T \hat{\alpha}_{G R} \\
\text { Pertimbangan untuk pemilihan }
\end{gathered}
$$
parameter bias pada $K$ berdasarkan pada nilai MSE. Untuk menentukan nilai $k_{j}$ digunakan pendekatan iteratif (Hoerl \& Kennard [3]) yang diawali dengan menentukan solusi kuadrat terkecil, didapatkan penduga awal untuk $k_{j}$

$$
k_{j}^{0}=\frac{\widehat{\sigma}^{2}}{\widehat{\alpha}_{j}{ }^{2}}, \quad j=1,2, \ldots, p
$$

Penduga awal dari $k_{j}$ digunakan untuk menghitung penduga awal generalized ridge dari

$$
\hat{\alpha}_{G R, j}^{0}=\left(\Lambda+\mathrm{K}^{0}\right)^{-1} Z^{\prime} y
$$

dengan, $\mathrm{K}^{0}=\operatorname{diag}\left(\mathrm{k}_{1}^{0}, \mathrm{k}_{2}^{0}, \ldots, \mathrm{k}_{\mathrm{p}}^{0}\right)$.

Selanjutnya pendugaan awal $\hat{\alpha}_{G R, j}^{0}$ digunakan untuk menghitung pendugaan $k_{j}^{1}$

$$
\mathrm{k}_{\mathrm{j}}^{1}=\frac{\widehat{\sigma}^{2}}{\left(\widehat{\alpha}_{G R, j}^{0}\right)^{2}}, \quad \mathrm{j}=1,2, \ldots, \mathrm{p}
$$

Nilai $\mathrm{k}_{\mathrm{j}}^{1}$ ini dapat digunakan menghitung pendugaan dari $\hat{\alpha}_{G R, j}^{1}$, dan seterusnya. Proses iterasi dilanjutkan hingga penduga parameter yang stabil didapatkan.

\subsection{Jackknife Ridge Regression}

Metode Jackknife diperkenalkan pertama kali oleh Hinkley pada tahun 1977 yang merupakan pengembangan dari metode Generalized Ridge Regression. Model awal seperti model umum regresi linear yaitu

$$
y=Z \gamma+u
$$

dengan $Z=X G$ dan $\gamma=G^{\prime} \beta . \quad G$ adalah matriks berukuran $n \times n$ yang kolomkolomnya dinormalisasi vektor eigen dari matriks $X^{\prime} X$. Matriks $Z^{\prime} Z=G^{\prime} X^{\prime} X G=\Lambda$. Penduga generalized regression dari $\gamma$ dapat ditulis sebagai:

$$
\begin{aligned}
\hat{\gamma}_{G R} & =(\Lambda+\mathrm{K})^{-1} Z^{\prime} y=A^{-1} Z^{\prime} y=A^{-1} \Lambda \hat{\gamma} \\
& =\left(I-A^{-1} K\right) \hat{\gamma}
\end{aligned}
$$

dengan $K=$ matriks diagonal dengan anggota $\left(k_{1}, k_{2}, \ldots, k_{p}\right), A=\Lambda+\mathrm{K}$. Pada $\gamma=G^{\prime} \beta$ dan $G^{\prime} G=I$, penduga generalized regression (GRE) dari $\beta$ adalah:

$$
\hat{\beta}_{G R}=G \hat{\gamma}_{G R R}=A^{-1}{ }_{*} X^{\prime} y
$$

dengan $A_{*}=X^{\prime} X+K$.

Menurut Hinkley (1997) metode Jackknife berasal dari $\hat{\gamma}_{G R}$ sebagai berikut:

$$
\hat{\gamma}_{J R R}=\left[I-\left(A^{-1} K\right)^{2}\right] \hat{\beta}_{L S}
$$

Aplikasi metode Jackniffe dihitung dengan mentransformasi ulang agar mendapatkan penduga parameter dari regresi awal.

Penduga jackknife ridge diperoleh dengan langka-langkah sebagai berikut:

$$
\begin{aligned}
\hat{\beta}_{J R} & =G \hat{\gamma}_{J R R} \\
\hat{\beta}_{J R} & =G\left[I+\left(A^{-1} K\right)\right]\left[I-\left(A^{-1} K\right)\right] \hat{\beta}_{L S} \\
& =G\left[I+\left(A^{-1} K\right)\right]\left(A^{-1} \Lambda\right) \Lambda^{-1} Z^{\prime} y \\
& =G\left[I+\left(A^{-1} K\right)\right] A^{-1} G^{\prime} X^{\prime} y \\
& =\left[G A^{-1} G^{\prime}+G A^{-1} K A^{-1} G^{\prime}\right] X^{\prime} y
\end{aligned}
$$

karena

$$
A=Z^{\prime} Z+K=G^{\prime}\left[X^{\prime} X+G K G^{\prime}\right] G
$$


maka;

$$
\begin{aligned}
& G A^{-1} G^{\prime}=\left(X^{\prime} X+K_{*}\right)^{-1}=A_{*}^{-1} \quad \text { dan } \\
& G A^{-1} K A^{-1} G^{\prime}=A_{*}^{-1} K_{*} A_{*}^{-1}
\end{aligned}
$$

dengan $K_{*}=G K G^{\prime}$

Setelah mendapatkan penduga koefisien regresi dari metode Jackknife Ridge Regression, perlu dipastikan apakah peubahpeubah bebas yang terlibat dalam model sudah tidak mengindikasikan adanya multikolinearitas dengan kembali melihat nilai Variance Inflation Factors (VIF). $\operatorname{VIF}_{j}(K)$ adalah fungsi dari $\mathrm{K}$ yang merupakan unsur diagonal ke $\mathrm{j}$ dalam matriks;

$$
\left(X^{\prime} X+K\right)^{-1} X^{\prime} X\left(X^{\prime} X+K\right)^{-1}
$$

Apabila nilai VIF dari masing-masing peubah bebas $\leq 5$ maka dipastikan bahwa peubahpeubah bebas sudah terbebas dari masalah multikolinearitas

\section{METODE PENELITIAN}

Penelitian ini menggunakan data sekunder yang merupakan data yang diperoleh secara tidak langsung. Dalam hal ini data yang digunakan adalah data mengenai kebutuhan akan tenaga kerja pada 17 Rumah Sakit Angkatan Laut U.S dari Tabel 13.3 dalam buku Bowerman dan O'Connel(1997).

Langkah-langkah yang dilakukan dalam metode penelitian ini adalah: 1) Mengkonfirmasi adanya multikolinearitas dengan melihat nilai VIF, 2) Melakukan analisi regresi linear berganda pada data, 3) Membakukan data, 4) Melakukan proses orthogonalisasi pada peubah-peubah bebas, 5) Menentukan nilai $\mathrm{K}$ yang merupakan matriks diagonal dengan anggota $\left(k_{1}, k_{2}, \ldots, k_{5}\right)$ dan penduga koefisien generalized ridge dari peubah bebas orthogonal dengan menggunakan metode iterasi. Pendugaaan awal untuk $k_{j}^{0}=\frac{\widehat{\sigma}^{2}}{\widehat{\gamma}_{j}^{2}}$, digunakan untuk menghitung parameter generalized ridge untuk peubah bebas orthogonal: $\hat{\gamma}_{G R}=(\Lambda+$ $\mathrm{K})^{-1} Z^{\prime} y$, 6) Menentukan penduga awal jackknife ridge regression yaitu $\hat{\gamma}_{J R}=$ $\left[I-\left(A^{-1} K\right)^{2}\right] \hat{\beta}_{L S}$, 7) Mentransformasikan penduga awal jackknife ridge regression yaitu
$\hat{\beta}_{J R}=G \hat{\gamma}_{J R}$ [2], 8) Menguji model jackknife ridge regression dan mendeteksi tidak adanya multikolinearitas dengan melihat nilai VIF, 9) Menguji kelayakan model yang dihasilkan jackknife ridge regression dengan model yang dihasilkan generalized ridge regression dengan melihat nilai MSE.

\section{HASIL DAN PEMBAHASAN}

4.1. Mendeteksi Adanya Multikolinearitas pada Model Regresi

Langkah yang dilakukan dalam mendeteksi adanya multikolinearitas dengan menggunakan metode kuadrat terkecil terhadap data kebutuhan tenaga kerja di 17 Rumah Sakit Angkatan Laut U.S yang ditunjukkan pada tabel penduga koefisien regresi (Tabel 1).Hasil analisis regresi linear berganda dengan menggunakan metode kuadrat terkecil terhadap data kebutuhan akan tenaga kerja pada 17 Rumah Sakit Angkatan Laut U.S menghasilkan model regresi linear berganda yaitu $\mathrm{Y}=1963-15,9$ $X_{1}+0,0559 X_{2}+1,59 X_{3}-4,22 X_{4}-394 X_{5}$.

Setelah mendapatkan model regresi, langkah selanjutnya melakukan uji kecocokan model regresi secara simultan dengan melakukan uji F. Dalam melakukan uji $\mathrm{F}$ hipotesis yang digunakan sebagai berikut:

$$
\begin{gathered}
H_{0}: \beta_{1}=\beta_{2}=\cdots=\beta_{p-1}=0 \\
H_{1}: \beta_{k(k-1, \ldots, p-1)} \neq 0 \text { minimal untuk satu } \\
\text { nilai } \mathrm{k}, \mathrm{k}=1,2, \ldots, p-1
\end{gathered}
$$

dengan kaidah keputusan tolak $H_{0}$ apabila $p$-value $<\alpha$ dan begitu juga sebaliknya. Dengan menggunakan tingkat toleransi $(\alpha)$ sebesar 0,05, maka dari Tabel 2 didapatkan kesimpulan bahwa minimal ada peubah bebas yaitu $\mathrm{X}_{1}, \mathrm{X}_{2}, \mathrm{X}_{3}, \mathrm{X}_{4}$, dan $\mathrm{X}_{5}$ berpengaruh signifikan terhadap model

Langkah selanjutnya adalah melakukan pengujian model regresi secara parsial (uji $t$ ) yang bertujuan untuk mengetahui signifikan atau tidaknya pengaruh masing-masing peubah bebas terhadap peubah terikat. Dalam melakukan uji $t$ hipotesis yang digunakan sebagai berikut: 
$H_{0}: \beta_{k}=0$ (peubah bebas $\mathrm{X}$ secara individu tidak berpengaruh secara signifikan terhadap nilai dugaan $\mathrm{Y}$ )

$H_{0}: \beta_{k} \neq 0$ (peubah bebas $\mathrm{X}$ secara individu berpengaruh secara signifikan terhadap nilai dugaan $\mathrm{Y}$ )

dengan kaidah keputusan tolak $H_{0}$ apabila $p$ value $<\alpha$ dan begitu juga sebaliknya.

Tabel 1 Penduga Koefisien Regresi
Dari Tabel 1 dengan menggunakan tingkat toleransi $(\alpha)$ sebesar 0,05 , maka terdapat empat peubah yang nilai tidak signifikan $X_{1}$, $\mathrm{X}_{3}, \mathrm{X}_{4}$, dan $\mathrm{X}_{5}$.

\begin{tabular}{|c|r|r|r|r|r|}
\hline Predictor & \multicolumn{1}{|c|}{ Coef } & SE Coef & \multicolumn{1}{|c|}{$T$} & \multicolumn{1}{c|}{ P } & \multicolumn{1}{c|}{ VIF } \\
\hline Constant & 1963 & 1071 & 1,83 & 0,094 & \\
\hline $\mathrm{X}_{1}$ & $-15,85$ & 97,65 & $-0,16$ & 0,874 & 9597,6 \\
\hline $\mathrm{X}_{2}$ & 0,05593 & 0,02126 & 2,63 & 0,023 & 7,9 \\
\hline $\mathrm{X}_{3}$ & 1,59 & 3,092 & 0,51 & 0,617 & 8933,1 \\
\hline $\mathrm{X}_{4}$ & $-4,219$ & 7,177 & $-0,59$ & 0,569 & 23,3 \\
\hline $\mathrm{X}_{5}$ & $-394,3$ & 209,6 & $-1,88$ & 0,087 & 4,3 \\
\hline
\end{tabular}

Tabel. 2 Analisis Ragam

\begin{tabular}{|c|c|c|c|c|c|}
\hline Source & DF & SS & MS & F & P \\
\hline Regression & 5 & 490177488 & 98035498 & 237,79 & 0,000 \\
\hline Residual Error & 11 & 4535052 & 412277 & & \\
\hline Total & 16 & 494712540 & & & \\
\hline
\end{tabular}

Namun kesimpulan yang berbeda didapat ketika melakukan pengujian univariat yaitu semua peubah bebas berpengaruh signifikan terhadap model. Setelah melakukan uji parsial didapatkan dari lima peubah bebas terdapat empat peubah bebas yang tidak berpengaruh secara signifikan terhadap model yaitu $\mathrm{X}_{1}, \mathrm{X}_{3}, \mathrm{X}_{4}$, dan $\mathrm{X}_{5}$. Pada hasil analisis regresi linear berganda diperoleh nilai $R^{2}$ yang besar yaitu 0,987 tetapi tidak diikuti dengan hasil uji hipotesis yang berpengaruh signifikan dari masing-masing koefisien regresi. Hal ini mengindikasikan adanya penyimpangan yang terjadi pada model, dimana seharusnya minimal terdapat tiga atau separuh dari semua peubah bebas yang berpengaruh signifikan terhadap model.

Penyimpangan-penyimpangan di atas diakibatkan oleh koefisien regresi yang tidak dapat diduga dengan tepat. Hal tersebut mengindikasikan adanya pelanggaran terhadap asumsi pendugaan parameter menggunakan metode kuadrat terkecil yaitu asumsi multikolinearitas. Untuk mengetahui adanya multikolinearitas pada peubah bebas akan dilakukan analisis terhadap nilai koefisien korelasi antar peubah bebas dan nilai VIF dari masing-masing peubah bebas.

Untuk mendeteksi adanya multikolinearitas pada peubah akan dilihat dari nilai korelasi antar peubah dan nilai VIF dari setiap peubah bebas.

Dari Tabel 3 menunjukkan bahwa korelasi antar peubah bebas cukup besar yaitu mendekati satu yang berarti bahwa terjadi kolinearitas yang kuat antar peubah bebas, namun korelasi antara $\mathrm{X}_{5}$ dengan peubah bebas yang lain tidak sekuat terhadap peubah bebas lainnya. Dari sini dapat disimpulkan bahwa terjadi multikolinearitas antar peubah bebas. Untuk memperkuat kesimpulan tersebut hal ini 
dipertegas dengan melihat nilai VIF dari masing-masing peubah bebas.

Tabel 3. Koefisien Korelasi Antar Peubah

\begin{tabular}{|c|c|c|c|c|c|}
\hline & $\mathrm{X}_{1}$ & $\mathrm{X}_{2}$ & $\mathrm{X}_{3}$ & $\mathrm{X}_{4}$ & $\mathrm{X}_{5}$ \\
\hline $\mathrm{X}_{1}$ & 1 & 0,9073 & 0,999 & 0,9356 & 0,6711 \\
\hline $\mathrm{X}_{2}$ & & 1 & 0,9071 & 0,9104 & 0,4466 \\
\hline $\mathrm{X}_{3}$ & & & 1 & 0,9331 & 0,6711 \\
\hline $\mathrm{X}_{4}$ & & & & 1 & 0,4628 \\
\hline $\mathrm{X}_{5}$ & & & & 1 \\
\hline
\end{tabular}

Tabel 4. Nilai VIF Peubah Bebas

\begin{tabular}{|r|r|}
\hline Predictor & \multicolumn{1}{|c|}{ VIF } \\
\hline$X_{1}$ & 9597,6 \\
\hline$X_{2}$ & 7,9 \\
\hline$X_{3}$ & 8933,1 \\
\hline$X_{4}$ & 23,3 \\
\hline$X_{5}$ & 4,3 \\
\hline
\end{tabular}

Nilai VIF pada Tabel 4 menunjukkan bahwa peubah bebas $\mathrm{X}_{1}, \mathrm{X}_{2}, \mathrm{X}_{3}$, dan $\mathrm{X}_{4}$ mengindikasikan bahwa keempat peubah bebas terlibat masalah multikolinearitas karena nilai VIF lebih dari 5. Dari hasil uraian di atas, maka dapat disimpulkan bahwa model mengandung multikolinearitas. Untuk mengatasi masalah itu diperlukan metode alternatif yaitu jackknife ridge regression.

\subsection{Pembakuan Peubah dengan Pemusatan dan Penskalaan}

Pembakuan (Standardized) peubah dilakukan dengan pemusatan dan penskalaan (Centering and Scaling) untuk meminimumkan kesalahan pembulatan[5]. Peubah baru dari hasil pembakuan centering dan scaling dengan rumus sebagai berikut:

$$
\begin{gathered}
Y_{i}^{*}=\frac{y_{i}}{S_{y}}=\frac{Y_{i}-\bar{Y}}{S_{y}} \\
z_{k i}=\frac{x_{k i}}{S_{k}}=\frac{X_{k i}-\bar{X}_{k}}{S_{k}}
\end{gathered}
$$

Setelah data dibakukan melalui centering dan scaling, dilakukan analisis regresi berganda terhadap data. Hasil yang didapat ternyata nilai VIF data kebutuhan tenaga kerja di 17 rumah sakit angkatan laut U.S untuk $\mathrm{X}_{1}, \mathrm{X}_{2}, \mathrm{X}_{3}$, dan $\mathrm{X}_{4}$ masih lebih besar dari 5. Hal ini menandakan bahwa data masih mengalami masalah multikoliearitas.

\subsection{Penyelesaian Masalah Multikolinearitas dengan Jackknife Ridge Regression}

Pada analisis regresi dengan menggunakan Jackknife Ridge Regression, data yang digunakan adalah data yang sudah mengalami proses centering dan scaling. Untuk mengatasi masalah multikolinearitas pada metode Jackknife Ridge Regression dengan menambahkan konstansa bias yang berbeda $\left(k_{1}, k_{2}, \ldots, k_{p}\right)$ pada diagonal utama matriks $X^{\prime} X$ dan memperkecil nilai masingmasing konstanta bias dalam persamaan kuadrat terkecil setelah sebelumnya peubahpeubah bebasnya mengalami proses orthogonalisasi.

Nilai konstanta bias $k_{1}, k_{2}, \ldots, k_{5}$ diperoleh melalui proses iterasi sampai ditemukan penduga koefisien regresi yang stabil. Iterasi berhenti pada iterasi kedua. Nilai konstanta bias $k_{1}, k_{2}, \ldots, k_{5}$ yang diperoleh dari iterasi kedua yaitu $34,8536,7,12881 \times 10^{4}$, $4,8317 \times 10^{8}, 7,21441 \times 10^{3}, 1,9907 \times 10^{7}$.

Langkah selanjutnya adalah pendugaan koefisien regresi untuk Jackknife Ridge Regression pada peubah awal dan nilai VIF dari masing-masing peubah dapat dilihat pada Tabel 5. Analisis ragam untuk model Jakknife Ridge Regression dapat dilihat pada Tabel 6. 
Tabel 5. Penduga Koefisien Jackknife Ridge Regression

\begin{tabular}{|c|c|c|c|c|c|c|}
\hline $\begin{array}{c}\text { Independe } \\
n t \\
\text { Variabel }\end{array}$ & $\begin{array}{c}\text { Regression } \\
\text { Coefficient }\end{array}$ & $\begin{array}{c}\text { Standard } \\
\text { Error }\end{array}$ & $\begin{array}{c}\text { Standardized } \\
\text { Regresssion } \\
\text { Coefficient }\end{array}$ & VIF & $\mathrm{t}_{0}$ & $\mathrm{t}_{0.025,11}$ \\
\hline Intercept & $-2.014,64$ & & & & & \\
\hline $\mathrm{X}_{1}$ & 7,09463 & 2,30785 & 0,2054 & $7,777 \times 10^{-4}$ & 3,0741 & 2,201 \\
\hline $\mathrm{X}_{2}$ & 0,05013 & 0,0174 & 0,1918 & $1,8781 \times 10^{-10}$ & 2,870 & 2,201 \\
\hline $\mathrm{X}_{3}$ & 0,23270 & 0,07574 & 0,2053 & $4,0468 \times 10^{-18}$ & 3,0723 & 2,201 \\
\hline $\mathrm{X}_{4}$ & 10,04817 & 3,4426 & 0,1950 & $1,8282 \times 10^{-8}$ & 2,9187 & 2,201 \\
\hline $\mathrm{X}_{5}$ & 495,68 & 234,618 & 0,1412 & $2,4605 \times 10^{-15}$ & 2,112 & 2,201 \\
\hline
\end{tabular}

Tabel 6. Analisis Ragam Jackknife Ridge Regression

\begin{tabular}{|c|r|r|r|r|r|}
\hline Source & \multicolumn{1}{|c|}{ DF } & \multicolumn{1}{c|}{ SS } & \multicolumn{1}{c|}{ MS } & \multicolumn{1}{c|}{$\mathrm{F}_{0}$} & \multicolumn{1}{c|}{$\mathrm{F}_{(0.05,5,11)}$} \\
\hline Regression & 5 & 372.031 .338 & 74.406 .267 & 33,66 & 3,20 \\
\hline Residual Error & 11 & 24.310 .231 & 2.210 .021 & & \\
\hline Total & 16 & 494.712 .540 & & & \\
\hline
\end{tabular}

Model regresi untuk metode Jackknife Ridge Regression adalah $Y=-2.014,64+$ $7,094 X_{1}+0,05013 X_{2}+0,2327 X_{3}+$ $10,0481 X_{4}+495,68 X_{5}$. Metode Jackknife Ridge Regression dapat mengatasi masalah multikolinearitas. Pada Tabel 5 terlihat bahwa nilai VIF dari masing-masing peubah bebas yang dihasilkan lebih kecil dari 5 yang berarti masing-masing peubah bebas pada model sudah tidak lagi terlibat masalah multikolinearitas. Nilai koefisien determinasi yang dihasilkan sebesar 0,9940 dengan MSE sebesar 2.210.021.

Dari hasil yang didapatkan pada Tabel 6 diperoleh nilai $F_{0}$ sebesar 33,66 maka $H_{0}$ ditolak yang berarti bahwa semua peubah bebas mempunyai pengaruh yang signifikan pada model. Langkah selanjutnya adalah menguji masing-masing pengaruh peubah bebas terhadap model dengan menggunakan uji $t$. Nilai $t_{0}$ dari masing-masing peubah bebas dapat dilihat pada tabel 5, maka terdapat satu peubah bebas yang tidak signifikan yaitu $X_{5}$.

\section{SIMPULAN}

Dari penelitian yang dilakukan dapat ditarik beberapa kesimpulan yaitu:

1. Metode Jackknife Ridge Regression dapat mengatasi masalah multikolinearitas dengan baik. Hal ini dapat dilihat dari nilai VIF setiap peubah bebas lebih kecil dari 5.

2. Metode Jackknife Ridge Regression menghasilkan MSE sebesar 2.210.021. Hal ini menunjukkan Jackknife Ridge Regression memiliki galat atau error yang kecil.

3. Metode Jackknife Ridge Regression menghasilkan nilai koefisien determinasi $\left(R^{2}\right)$ sebesar 0.9940. Ini menunjukkan peubah bebas pada metode Jackknife Ridge Regression dapat menggambarkan keragaman peubah tak bebas sebesar 99,40 $\%$.

Metode Generalized Ridge Regression dan Jackknife Ridge Regression dapat mengatasi masalah multikolinearitas dengan baik namun terdapat metode yang merupakan kombinasi dari kedua metode tersebut yaitu metode Modified Jackknife Ridge Regression yang diusulkan oleh Batah et al (2008) yang 
dapat digunakan sebagai referensi untuk penelitian selanjutnya.

\section{DAFTAR PUSTAKA}

[1] Bowerman, B. \& O'Connel, R. T., 1997. Applied Statistics Improving Business Processes. 1 ed. United States of America: Tom Casson.

[2] Gore, Sharad, Thekke V. Ramanathan \& Feras Sh. M. Batah, 2008. The Efficiency Of Modified Jackknife And Ridge Type Regression Estimators: A Comparison. Surveys in Mathematics and its Applications, Volume III, pp. 111-122.

[3] Hoerl, A.E. and R.W. Kennard. 1970. "Ridge Regression: Applications to Nonorthogonal Problems". Technometrics, Vol. 12, No. 1. (Feb., 1970b), pp. 69-82. http://statgen.ucr.edu/download/course/S TAT288/hoerl70b.pdf. Diakses tanggal 14 Juni 2012.

[4] Montgomery, D.C. and E.A. Peck. 1991. Introduction to Linear Regression Analysis, Second Edition. New York: John Wiley and Sons, Inc.

[5] Neter, J., Wasserman, W. \& Kutner, M. H., 1997. Model Linear Terapan. 2 ed. Diterjemahkan oleh Bambang Sumantri. Bogor: Jurusan Statistika FMIPA IPB.

[6] Ozkale, M. R., 2008. A Jackknifed Ridge Estimator in The Linear Regression Model with Heteroscedastic or Correlated Errors. Statistics and Probability Letters, Volume I, pp. 3159-3169. 